\title{
PERENCANAAN SISTEM PENANGANAN BAGASI PADA TERMINAL 2 DI BANDAR UDARA JUANDA SURABAYA
}

\author{
Jurusan Teknik Sipil, Fakultas Teknik Sipil dan Perencanaan, Institut Teknologi Sepuluh Nopember (ITS) \\ Jl. Arief Rahman Hakim, Surabaya 60111 \\ Email : ervina@ce.its.ac.id
}

\begin{abstract}
Abstrak - Bandar Udara Internasional Juanda Surabaya memberikan pelayanan jasa kebandarudaraan dengan menjaga kenyamanan, keselamatan, dan keamanan pengguna jasa. Salah satu komponen terpenting dalam memberikan pelayanan pada pengguna jasa adalah sistem penanganan bagasi. Sistem penanganan bagasi di Terminal 2 Juanda masih menggunakan manual, Untuk mengetahui penanganan bagasi pada terminal 2 saat ini diperlukan beberapa peninjauan langsung untuk mengetahui berapa jumlah arus pergerakan bagasi, dan bagaimana kinerja penanganan bagasi eksisting pada terminal 2 Bandara Juanda. Tugas akhir ini menganalisis kinerja penanganan bagasi eksisting di terminal 2 serta merencanakan penanganan bagasi dengan hold baggage screening. Hold Baggage Screening merupakan integrasi lengkap antara Bagasi Sistem Penanganan Conveyor dan Mesin Xray terletak pada satu garis, mesin xray berguna untuk mendeteksi keamanan pada bagasi namun tetap berada belt conveyor.Hasil menunjukkan bahwa pergerakan yang berangkat melalui terminal 2 adalah 6.840 pax, 57 flights, dan 4.419 bags, waktu minimal yang dibutuhkan memroses bagasi setelah check in sampai ke pesawat 76 menit 53detik dan maksimal 115 menit 27 detik. Rata-rata bagasi yang dibawa setiap penumoang adalah 2 buah. Luas area penanganan bagasi pada terminal 2 adalah $585 \mathrm{~m}^{2}$ dengan kemampuan menangani bagasi sebanyak 403 bags/jam. Berdasarkan perhitungan tersebut, maka pada terminal 2 disarankan menggunakan sistem penanganan bagasi otomatis dan untuk dapat menerapkan system penanganan bagasi otomatis dengan hold baggage screening diperlukan conveyor inline dan mesin hold baggage screening.
\end{abstract}

Kata Kunci: Bagasi, Sistem Penanganan Bagasi, Hold Baggage Screening, Kinerja, Terminal 2 Bandar Udara Juanda Surabaya

\section{PENDAHULUAN}

Penanganan bagasi memiliki peran penting dalam menjaga kenyamanan penumpang pesawat udara dan memproses bagasi tersebut sampai dapat diangkut bersamaan dalam satu pesawat dengan penumpangnya. Dalam proses check-in di suatu bandara penumpang datang ketempat check-in counter lalu pihak checkin counter melihat tiket dan menimbang barang bawaan penumpang lalu memberikan boarding pass sebagai tanda bukti penumpang dapat melakukan penerbangan. Tetapi selama ini penumpang tidak tahu bagaimana proses barang bawaan yang sudah diserahkan di check-in counter sampai ke bagasi pesawat. Seiring dengan pertumbuhan pergerakan penerbangan (penumpang dan pesawat), saat ini teknologi yang diterapkan untuk penanganan bagasi penumpang telah berkembang pesat. Beberapa airport modern telah mengimplementasikan automated Baggage Handling System (BHS) / Hold Baggage Screening (HBS) sebagai solusi penanganan bagasi yang efisien, efektif, dan aman (secure) terhadap barang yang bersifat membahayakan keselamatan penerbangan [2].

\section{METODOLOGI PENELITIAN}

\section{A. Identifikasi Permasalahan}

Kondisi penanganan bagasi eksisting terminal 2 keberangkatan Bandar Udara Juanda Surabaya sudah menggunakan Baggage Handling System namun tidak secara inline dan tidak otomatis melainkan dilakukan secara manual membutuhkan pekerja dengan mendorong bagasi melalui gravity roller untuk masuk ke dalam mesin $\mathrm{x}$-ray [1]. Sehingga keterlibatan pekerja sangat mempengaruhi.

a) Current State: Pemrosesan bagasi saat ini melibatkan pekerja untuk mengontrol isi bagasi melalui monitor xray, disamping itu untuk memasukan bagasi kedalam mesin xray, pekerja lain melakukan penarikan bagasi diatas gravity roller.

b) Ideal State: Untuk menggantikan pekerja yang mengontol keamanan bagasi dan melakukan penarikan bagasi ke mesin xray direncanakan melengkapi Baggage Handling system dengan Hold Baggage Screening di Terminal 2 keberangkatan Bandar Udara Juanda Surabaya.

\section{B. Tahap Analisis Data}

Data yang diperoleh selanjutnya akan dianalisis menggunakan teori yang sudah ditentukan dalam tinjauan pustaka. Hasil dari analisis data ini nantinya akan menentukan sistem penanganan bagasi pada terminal 2 perlu atau tidak perlu penyempurnaan menggunakan Baggage Handling System - Hold Baggage Screening. Beberapa tahapannya adalah:

1. Tahap perhitungan arus penumpang, pesawat, dan bagasi [3].

2. Tahap evaluasi durasi bagasi berjalan dengan metode IATA [4].

3. Tahap evaluasi penanganan jumlah bagasi per jam dengan metode IATA.

4. Tahap analisis hubungan antara jumlah penumpang dan jumlah bagasi.

5. Tahap analisis hubungan jumlah bagasi dengan tujuan penerbangan.

6. Tahap analisis hubungan jumlah bagasi dengan jenis pesawat.

7. Tahap analisis waktu boarding penumpang dan loading bagasi.

8. Tahap analisis unloading bagasi dan penumpang kedatangan. 


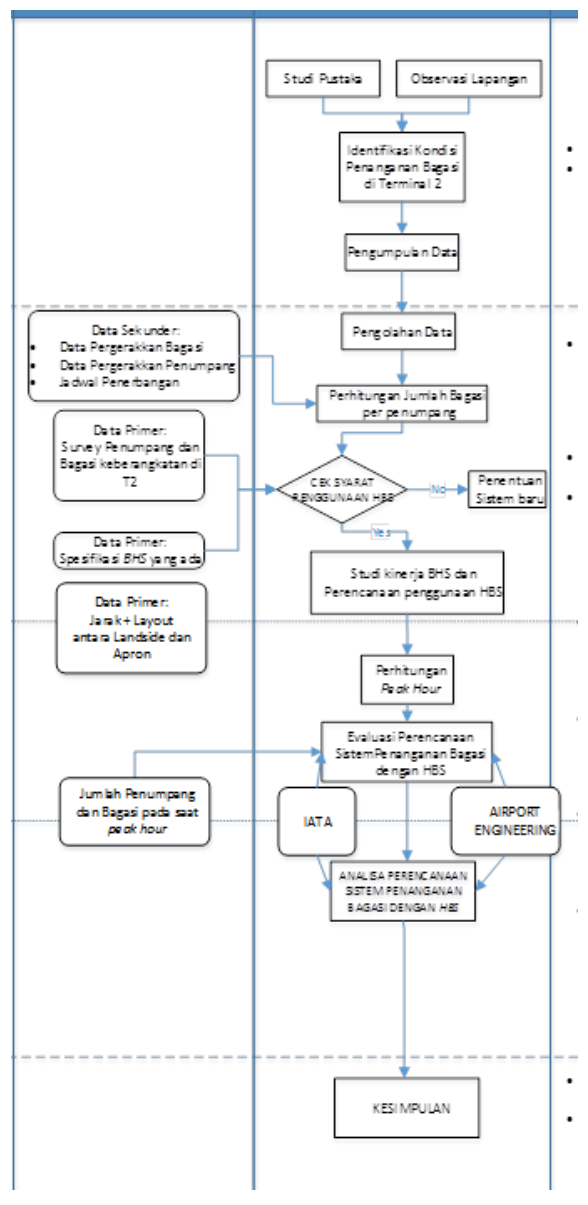

Gambar 1. Diagram Alir Penelitian

\section{ANALISIS}

Untuk mengetahui kinerja penanganan bagasi pada terminal 2 Bandar Udara Juanda Surabaya dibutuhkan data primer yaitu dengan melakukan survey lapangan pada keberangkatan terminal 2 Bandar Udara Juanda Surabaya. Data yang diperoleh antara lain: penerbangan yang beroperasi, tujuan penerbangan, jadwal penerbangan, jumlah penumpang, jumlah bagasi, waktu tempuh bagasi dari check in counter sampai ke bagian sorting, jumlah pekerja yang menangani bagasi ditempat sorting, waktu tempuh bagasi dari tempat sorting sampai ke pesawat, jumlah pekerja yang menangani bagasi dipesawat, waktu bagasi pesawat dibuka, waktu pemasangan conveyor bagasi ke pesawat, dan waktu bagasi pesawat ditutup.

Selain mencatat jumlah penumpang, bagasi, dan pekerja. Penulis juga mencatat waktu tempuh bagasi dan mengelompokkan menjadi beberapa bagian,

1. Waktu tempuh bagasi dari check in sampai ke sorting area.

2. Waktu yang diperlukan bagasi dari sorting area sampai proses muatan gerobak penuh.

3. Waktu yang diperlukan bagasi setelah dimuat sampai ke pesawat.

Tabel 1.

Hasil Survey Waktu Tempuh Bagasi

\begin{tabular}{|c|c|c|c|c|}
\hline \multirow{2}{*}{$\begin{array}{c}\text { Jumlah } \\
\text { Penerbangan }\end{array}$} & \multicolumn{3}{|c|}{ WAKTU TEMPUH BAGASI } & $\begin{array}{c}\text { Total waktu tempuh } \\
\text { penanganan bagasi } \\
\text { (menit) }\end{array}$ \\
\hline 57 & $\begin{array}{c}\text { Check in - Sorting } \\
\text { (menit) }\end{array}$ & $\begin{array}{c}\text { Sorting - Koli } \\
\text { (menit) }\end{array}$ & $\begin{array}{c}\text { Koli - Pesawat } \\
\text { (menit) }\end{array}$ & \begin{tabular}{c} 
(ment) \\
\hline
\end{tabular} \\
\hline
\end{tabular}

Berdasarkan tabel 1 dapat diakumulasikan total waktu tempuh bagasi. Waktu tempuh bagasi dari check in sampai ke sorting dicatat pada saat bagasi pertama yang melalui check in counter sampai bagasi terakhir yang sampai di sorting area, waktu yang diperlukan bagasi dari sorting area sampai proses muatan ke gerobak dicatat saat bagasi pertama dinaikkan ke atas gerobak hingga bagasi terakhir masuk ke gerobak, serta waktu yang diperlukan bagasi setelah dimuat sampai ke pesawat dicatat pada saat gerobak pengangkut bagasi berjalan hingga sampai ke depan bagasi pesawat.

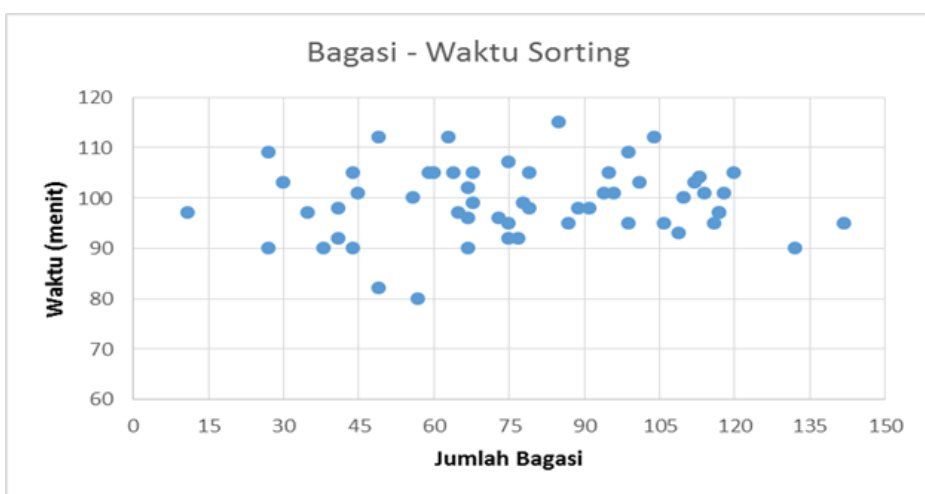

Gambar 2. Grafik Hubungan Bagasi dan Waktu Sorting

Berdasarkan gambar 2 menggambarkan hubungan antara jumlah bagasi dan waktu tempuh bagasi dari sorting hingga ke koli pengangkut bagasi. Banyaknya jumlah bagasi sama sekali tidak mempengaruhi waktu bagasi dari sorting hingga ke koli pengangkut.

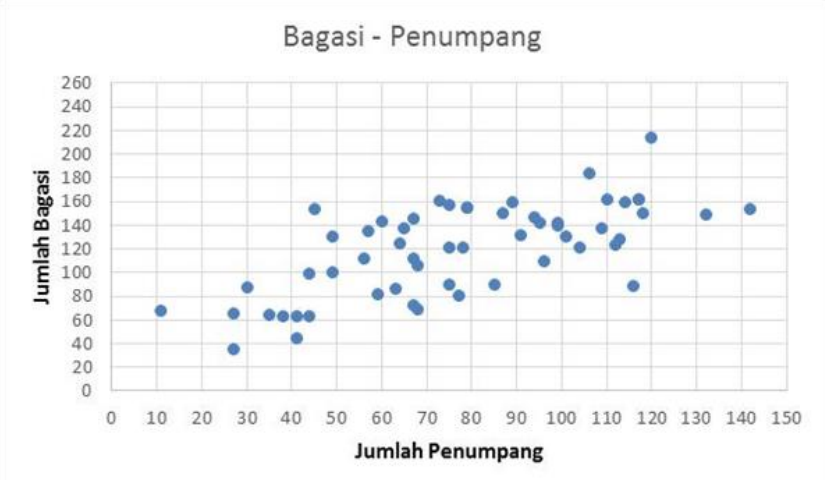

Gambar 3. Grafik hubungan jumlah bagasi dan penumpang

Grafik 3 menggambarkan jumlah penumpang dan bagasi yang melalui terminal 2 keberangkatan Bandar udara juanda Surabaya, grafik tersebut menunjukkan semakin banyak penumpang yang berangkat, maka semakin banyak pula bagasi yang akan diangkut oleh pesawat.

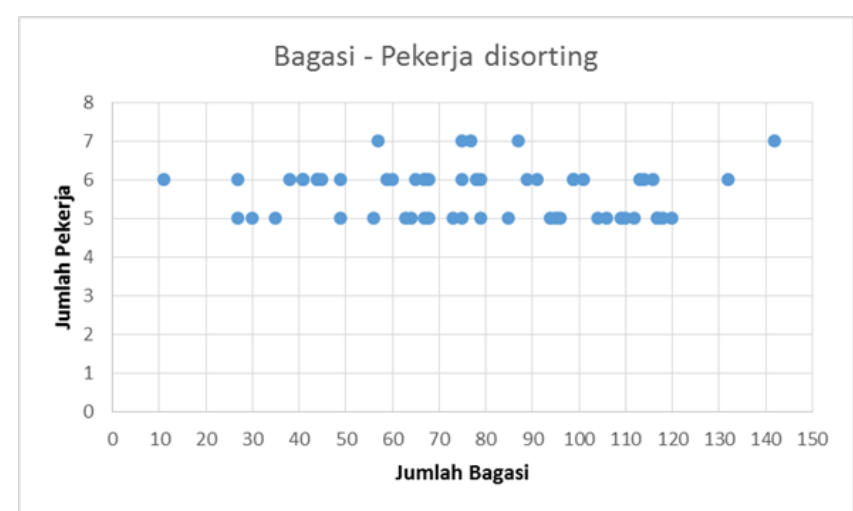

Gambar 4. Grafik Jumlah Bagasi dan Pekerja di Sorting 


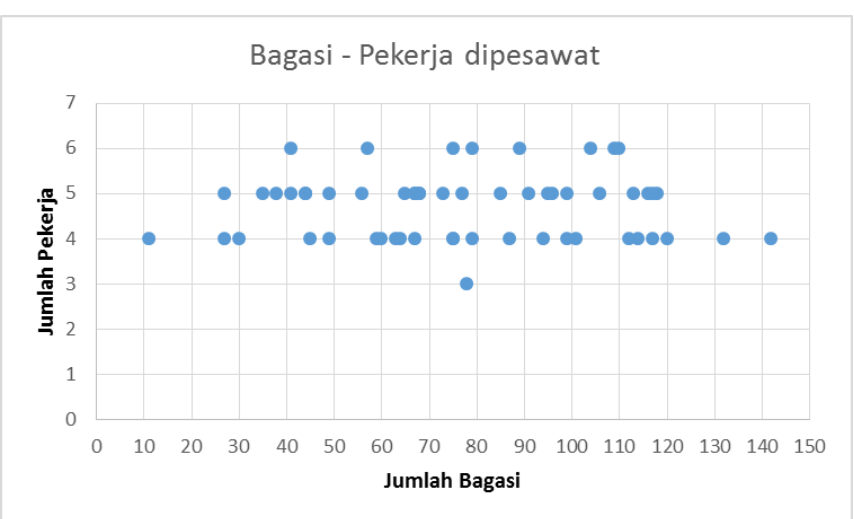

Gambar 5. Grafik Jumlah Bagasi dan pekerja di sorting

Berdasarkan gambar 4 dapat diketahui bahwa jumlah pekerja yang menangani bagasi dan jumlah bagasi tidak berkorelasi sehingga penanganan bagasi akan lebih lama apabila jumlah bagasi semakin banyak. Sedangkan berdasarkan gambar 5 terjadi hal yang sama seperti pada pekerja disorting, jumlah pekerja yang menangani bagasi dipesawat dan bagasi tidak dipengaruhi oleh jumlah bagasi.

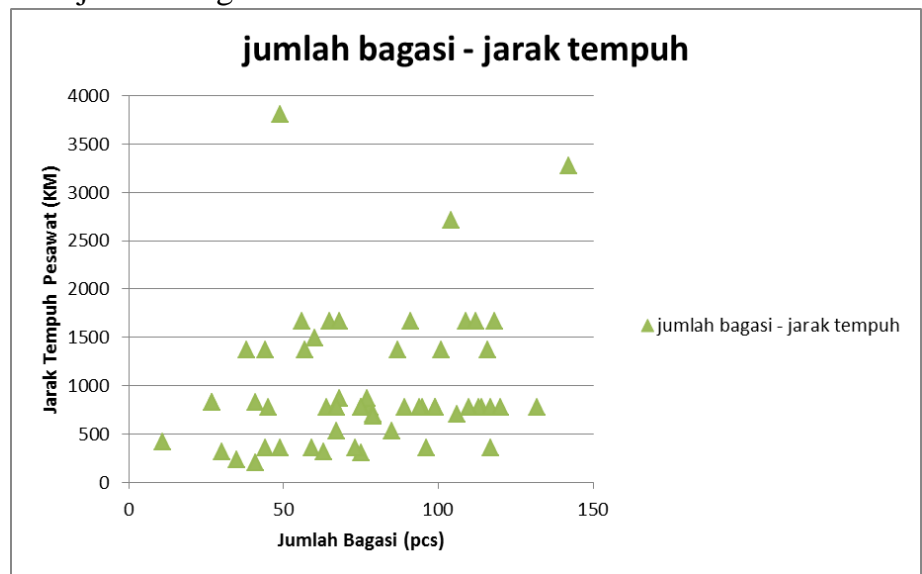

Gambar 6 Grafik hubungan jumlah bagasi dan jarak tempuh

Berdasarkan gambar 6 dapat diketahui jarak tempuh memiliki pengaruh yang kecil terhadap jumlah bagasi, jumlah bagasi terbanyak tidak dipengaruhi oleh jarak tempuh.

Berdasarkan data yang didapat 5 tahun terakhir maka diketahui perhitungan peak hour penanganan bagasi pada terminal 2 bandar udara juanda Surabaya.

1. Tahun 2011

$$
\frac{\text { jumlah bagasi per hari }}{\text { operasional terminal }}=\frac{5509}{16}=344 \frac{\text { bags }}{\text { jam }}
$$

2. Tahun 2012

$$
\frac{\text { jumlah bagasi per hari }}{\text { operasional terminal }}=\frac{6300}{16}=394 \frac{\mathrm{bags}}{\text { jam }}
$$

3. Tahun 2013

$$
\frac{\text { jumlah bagasi per hari }}{\text { operasional terminal }}=\frac{6504}{16}=407 \frac{\mathrm{bags}}{\text { jam }}
$$

4. Tahun 2014

$$
\frac{\text { jumlah bagasi per hari }}{\text { operasional terminal }}=\frac{5869}{16}=367 \frac{\mathrm{bags}}{\text { jam }}
$$

5. Tahun 2015

$$
\frac{\text { jumlah bagasi per hari }}{\text { operasional terminal }}=\frac{6453}{16}=403 \frac{\text { bags }}{\text { jam }}
$$

Dari perhitungan tersebut dapat diketahui lalu lintas bagasi keberangkatan diterminal 2 pada tahun 2015 adalah 403 bagasi setiap jam. Sedangkan berdasarkan International Air Transport Association apabila lalu lintas bagasi mencapai <999bags/jam maka dapat digunakan penanganan bagasi manual maupun otomatis.

\section{KESIMPULAN DAN SARAN}

Makalal ini memaparkan studi kinerja penanganan bagasi pada Terminal 2 Bandar Udara Juanda Surabaya dengan cara mengevaluasi penanganan bagasi yang ada pada terminal tersebut. Studi kinerja yang dilakukan dengan cara pengamatan dan survey proses penanganan bagasi, proses penumpang datang sampai masuk pesawat, proses penumpang datang sampai menerima bagasi.

Dari hasil pengamatan yang telah dilakukan, diperoleh kesimpulan sebagai berikut.

1. Jumlah pergerakan yang berangkat melalui terminal 2 Bandar Udara Juanda Surabaya setiap harinya adalah

a. Jumlah penumpang : 6.840 pax

b. Jumlah pesawat : 57 flight

c. Jumlah bagasi : 4.419 bags

2. Waktu yang dibutuhkan memroses bagasi setelah check in sampai ke pesawat 76 menit 53 menit (minimal) dan 115 menit 27 detik (maksimal).

3. Rata-rata bagasi yang dibawa penumpang adalah 1 bag.

4. Luas area penanganan bagasi pada terminal 2 adalah $585 \mathrm{~m}^{2}$ dengan kemampuan menangani bagasi sebanyak $403 \mathrm{bags} / \mathrm{jam}$.

5. Waktu loading bagasi lebih lama dari boarding time penumpang, waktu yang dibutuhkan untuk loading bagasi pertama sampai ditutupnya pintu bagasi pesawat ialah 51 menit 31 detik, sedangkan rata-rata boarding time dimana penumpang pertama masuk pesawat sampai ditutupnya pintu pesawat membutuhkan 23 menit 6 detik. Waktu kinerja pelayanan bagasi atau ratarata waktu penumpang menunggu bagasi sampai bagasi pertama sampai pada ruangan pengambilan bagasi adalah 19 menit 2 detik. Rata-rata waktu perputaran bagasi pertama sampai bagasi terakhir adalah 14,25 menit. Sehingga berdasarkan analisa terhadap hasil pengamatan, pada terminal 2 dapat diterapkan sistem penanganan bagasi dengan automated Baggage Handling System / Hold Baggage Screening dengan perluasan area yang ada, menambah conveyor inline, serta mesin hold baggage screening

Analisis dalam tugas akhir ini memberikan gambaran proses penanganan bagasi pada Terminal 2 Bandar Udara Juanda Surabaya. Dimana dalam menganalisanya menggunakan data pengamatan dan teori yang ada pada IATA. Dalam analisis tersebut masih ada hal-hal penting yang perlu dianalisis lebih dalam berkaitan dengan perencanaan sistem penanganan bagasi dengan hold baggage screening.

\section{DAFTAR PUSTAKA}

[1] Angkasa Pura I0. "Proses Penanganan Bagasi." Jalan Ir. Haji Juanda, Surabaya, (2015).

[2] Ashford, Norman J. Mumayiz, Saleh A. Wright, Paul H. Fourth Edition. "Airport Engineering. Penerbit John Wiley \& Sons Inc". Canada. 2011.

[3] Angkasa Pura I. "Weekly Flight Schedule." Jalan Ir. Haji Juanda, Surabaya, (2015).

[4] International Air Transport Association. "Airport Development Reference Manual”. Montreal, Canada. (2004). 